\title{
Selecting PCR for the Diagnosis of Intestinal Parasitosis: Choice of Targets, Evaluation of In-House Assays, and Comparison with Commercial Kits
}

\author{
G. N. Hartmeyer, ${ }^{1,2}$ S. V. Hoegh, ${ }^{2}$ M. N. Skov, ${ }^{1,2}$ R. B. Dessau, ${ }^{3}$ and M. Kemp ${ }^{1,2}$ \\ ${ }^{1}$ Research Unit of Clinical Microbiology, Institute of Clinical Research Faculty of Health Science, \\ University of Southern Denmark, Odense, Denmark \\ ${ }^{2}$ Department of Clinical Microbiology, Odense University Hospital, Odense, Denmark \\ ${ }^{3}$ Department of Clinical Microbiology, Slagelse Hospital, Slagelse, Denmark
}

Correspondence should be addressed to G. N. Hartmeyer; gitte.hartmeyer@rsyd.dk

Received 9 May 2017; Accepted 31 July 2017; Published 30 August 2017

Academic Editor: Bernard Marchand

Copyright (C) 2017 G. N. Hartmeyer et al. This is an open access article distributed under the Creative Commons Attribution License, which permits unrestricted use, distribution, and reproduction in any medium, provided the original work is properly cited.

\begin{abstract}
Microscopy of stool samples is a labour-intensive and inaccurate technique for detection of intestinal parasites causing diarrhoea and replacement by PCR is attractive. Almost all cases of diarrhoea induced by parasites over a nine-year period in our laboratory were due to Giardia lamblia, Cryptosporidium species, or Entamoeba histolytica detected by microscopy. We evaluated and selected in-house singleplex real-time PCR (RT-PCR) assays for these pathogens in 99 stool samples from patients suspected of having intestinal parasitosis tested by microscopy. The strategy included a genus-specific PCR assay for C. parvum and C. hominis, with subsequent identification by a PCR that distinguishes between the two species. G. lamblia was detected in five and C. parvum in one out of 68 microscopy-negative samples. The performance of the in-house RT-PCR assays was compared to three commercially available multiplex test (MT-PCR) kit systems in 81 stool samples, collected in 28 microscopy-positive and 27 microscopy-negative samples from individuals suspected of intestinal parasitosis and in 26 samples from individuals without suspicion of parasitic infection. The in-house assays detected parasites in more samples from patients suspected of having parasitosis than did any of the kits. We conclude that commercial kits are targeting relevant parasites, but their performance may vary.
\end{abstract}

\section{Background}

Correct identification of microbial agents causing diarrhoea in humans is crucial for optimal treatment. Detection of disease-causing intestinal parasites is traditionally done by microscopic examination of stool samples. Over the last years this has been changed in favour of using PCR. Studies have shown that both sensitivity and specificity of PCR are better compared to microscopy [1-5]. Moreover, microscopy can lead to false conclusions, with harmless parasites being interpreted as disease-causing, while life-threatening parasites may not be detected. This has in particular been demonstrated for intestinal amoeba [6-10]. For estimating the true impact of parasitic intestinal infections, it is important to establish valid and reliable laboratory techniques for testing stool samples from patients. Use of optimized laboratory methods will improve patient safety through rapid and correct diagnosis, which leads to timely start of appropriate treatment.

The aim of this study was to evaluate the consequences of replacing microscopy by real-time PCR (RT-PCR) for detection of intestinal parasites causing diarrhoea. In order to do so, we first established which parasites were detected by microscopy in our laboratory over a period of nine years, to determine which parasites were relevant in our patient population. We determined which previously detected parasites would be missed by introducing a limited number of species-specific PCR assays and how many cases they represented. We then evaluated the performance of in-house singleplex RT-PCR assays for the three most important 
intestinal parasitic pathogens. Finally, the performance of three selected in-house RT-PCR assays for detection of Giardia lamblia, Cryptosporidium parvum/Cryptosporidium hominis, and Entamoeba histolytica was compared to those of three commercial multiplex real-time PCR (MT-PCR) kits.

Two specific objectives were defined: (1) evaluation of performance of species-specific in-house RT-PCR assays for detection of G. lamblia, C. parvum/C. hominis, and E. histolytica in stool samples submitted for examination for parasites; (2) comparison of the performance of the in-house RT-PCR assays with the performance of three commercial MT-PCR kits for detection of the same parasites.

\section{Methods}

2.1. Data Collection from the Laboratory Information System (LIS). Data on faecal samples examined for parasites from October 2005 to January 2015 was extracted from the electronic LIS. The total number of samples and patients and results of microscopy were registered.

2.2. Stool Samples. In total 125 stool samples, of which 99 were examined by microscopy on suspicion of parasitosis, were randomly collected from individuals with gastrointestinal complaints between June 2010 and January 2015. Ninety-nine of these samples were included for objective one (31 microscopy-positive and 68 microscopy-negative) and eighty-one (28 microscopy-positive and 27 microscopynegative) were included for testing objective two. In addition 26 samples from individuals without suspicion of parasitosis were included without microscopy for objective two.

For objective 1, a total of 99 samples were analysed by in-house RT-PCR. For objective 2, a total of 81 samples were analysed by in-house RT-PCR and by three commercial MTPCR kits. All samples were kept at $-80^{\circ} \mathrm{C}$ until PCR were performed.

2.3. Microscopy for Intestinal Parasites. Microscopic examination for the presence of ova and cysts was routinely performed by examination of iodine-stained wet-mount preparations after formalin-ethyl acetate concentration, at a magnification of $\times 400$ [11]. On specific request and when Cryptosporidium species, Cyclospora species, or Cystoisospora species was suspected from routine microscopy a smear stained by modified Ziehl-Neelsen technique was also examined [12].

2.4. In-House RT-PCR. For the in-house PCR assays, DNA was extracted by using NucliSENS easyMAG system (bioMérieux, France) in accordance with the manufacturer's instructions. Prior to DNA extraction, a cotton swab was submerged into the stool sample and suspended in $4 \mathrm{ml}$ physiological $\mathrm{NaCl}$ solution. An internal extraction and PCR control, phocine herpesvirus (PhHV laboratory strain) was added to each sample prior to DNA extraction [13]. The nucleic acids were eluted in $100 \mu \mathrm{l}$ and processed for PCR immediately.

Detection of the three intestinal parasites (G. lamblia, C. parvum/C. hominis, and E. histolytica) was performed as singleplex RT-PCR in 99 samples analysed as duplicate. One assay was tested for detection of G. lamblia, three were tested for C. parvum/C. hominis, and one assay (assay 3) was included to distinguish between C. parvum and C. hominis. Finally one assay for E. histolytica was tested, using primers and probes (Table 1) described previously [1, 4, 13-16].

The $25 \mu \mathrm{l}$ reactions mixture contained 1x TaqMan ${ }^{\circledR}$ Fast Universal PCR Master Mix, 2x No AmpErase ${ }^{\circledR}$ UNG (Thermo Fisher Scientific, Waltham, MA, USA), $1000 \mathrm{nM}$ of the primers, and $200 \mathrm{nM}$ of the probes and $5 \mu \mathrm{l}$ DNA eluate.

The real-time PCR was performed using an Applied Biosystems 7500 Fast Real-Time PCR Thermocycler (Thermo Fisher Scientific) with the following cycling conditions: $95^{\circ} \mathrm{C}$ for $20 \mathrm{sec}$, followed by $45 \mathrm{cycles}$ of $95^{\circ} \mathrm{C}$ for $3 \mathrm{sec}$ and $60^{\circ} \mathrm{C}$ for $30 \mathrm{sec}$.

The PCR products were analysed using Sequence Detection Software v.1.4 (Thermo Fisher Scientific). A manual cycle threshold was set to 0,1 with an automatic baseline. The sample was regarded as positive if the Ct-value was $\leq 42$ and had an exponential curve. Negative and positive extraction and PCR controls were included in all PCR analysis.

The singleplex in-house RT-PCR assays for G. lamblia, C. parvum/C. hominis (assay 1), and E. histolytica were collective called kit A and compared to three commercial MT-PCR kits, used in objective 2 on 79 samples.

2.5. Diagnostic Test Kits. Three different commercial kits available at the market were tested: $\mathrm{RIDA}^{\circledR} \mathrm{GENE}$ Parasitic Stool Panel (PG1705) from R-Biopharm AG, Darmstadt, Germany (kit B), LightMix ${ }^{\circledR}$ Modular Gastroenteritis Assays from TIB MOLBIOL, Berlin, Germany (kit C), and BD MAX $^{\mathrm{TM}}$ Enteric Parasite Panel from BD Diagnostic, Franklin Lakes, NJ, USA (kit D). DNA extraction for kits B and C was done as described for the in-house assays. For kit D, DNA extraction was done according BD MAX enteric parasite panel instructions on the BD MAX system. In all commercial kits, we used the internal control DNA, which was recommended and included in the kits. Seventy-nine samples were tested in duplicate in all three kits, in accordance with the manufacturer's instructions. For kit B the PCR assays were carried out using an Applied Biosystems 7500 Fast Real-Time PCR Thermocycler with the following cycling conditions: $1 \mathrm{~min}$ at $95^{\circ} \mathrm{C}$, followed by $45 \mathrm{cycles}$ of $95^{\circ} \mathrm{C}$ for $15 \mathrm{sec}$ and $60^{\circ} \mathrm{C}$ for $30 \mathrm{sec}$. For kit $\mathrm{C}$ the PCR assays were done on a Roche LightCycler $480^{\circledR}$ II real-time instrument with the following cycling conditions: $10 \mathrm{~min}$ at $95^{\circ} \mathrm{C}$, followed by 50 cycles of $95^{\circ} \mathrm{C}$ for $5 \mathrm{sec}, 62^{\circ} \mathrm{C}$ for $5 \mathrm{sec}$, and $72^{\circ} \mathrm{C}$ for $15 \mathrm{sec}$. For kit $\mathrm{D}$ analysing was done according $\mathrm{BD}$ MAX enteric parasite panel instructions on the BD MAX system. A positive result in kits was regarded positive, if one out of two duplicates was positive, used in objective 2 .

2.6. Analysis. McNemar's test was used for the statistical comparison of the paired data in objective 1 .

2.7. Ethics, Biobank, and Data Storage. The study is part of a Ph.D. project and approved by the Danish Data Protection Agency (j.nr. 2008-58-0035). All samples were stored at $-80^{\circ} \mathrm{C}$ in an approved research biobank established for the 


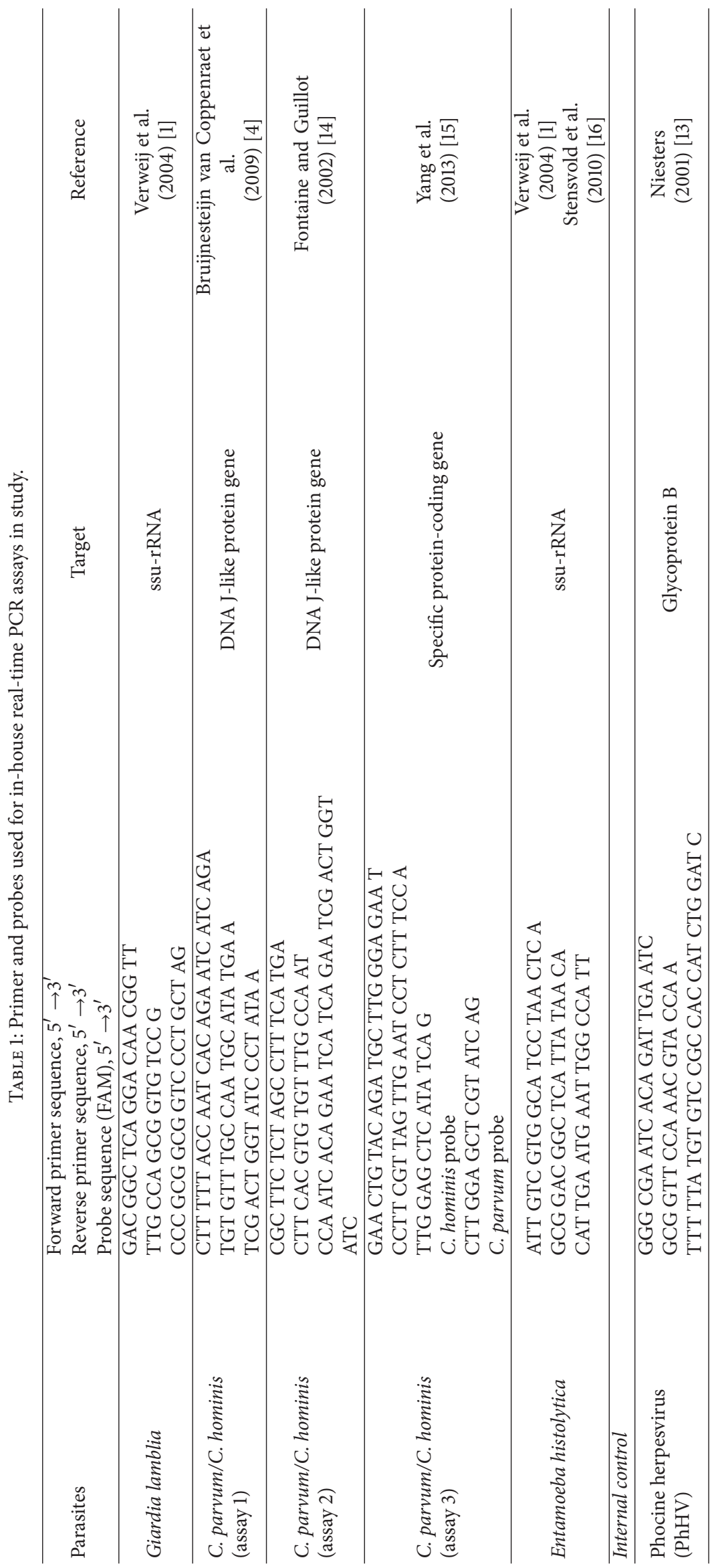


TABLE 2: Samples with discordant results obtained from different test kits.

\begin{tabular}{|c|c|c|c|c|c|c|c|c|c|}
\hline \multirow{2}{*}{$\begin{array}{l}\text { Sample } \\
\text { number }\end{array}$} & \multirow[b]{2}{*}{ Mic. } & \multicolumn{4}{|c|}{ Giardia } & \multicolumn{4}{|c|}{ Cryptosporidium } \\
\hline & & $\begin{array}{c}\text { Kit } \\
\text { A }\end{array}$ & $\begin{array}{c}\text { Kit } \\
\text { B }\end{array}$ & $\begin{array}{c}\text { Kit } \\
\text { C }\end{array}$ & $\begin{array}{c}\text { Kit } \\
\text { D }\end{array}$ & $\begin{array}{c}\text { Kit } \\
\text { A }\end{array}$ & $\begin{array}{c}\text { Kit } \\
\text { B }\end{array}$ & $\begin{array}{c}\text { Kit } \\
\text { C }\end{array}$ & $\begin{array}{c}\text { Kit } \\
\text { D }\end{array}$ \\
\hline 6 & Giardia & $0 / 0$ & $0 / 0$ & $0 / 0$ & $0 / 0$ & $0 / 0$ & $0 / 0$ & $0 / 0$ & $0 / 0$ \\
\hline 7 & Giardia & $+/+$ & $0 / 0$ & $+/ 0$ & $+/+$ & $0 / 0$ & $0 / 0$ & $0 / 0$ & $0 / 0$ \\
\hline 8 & Giardia & $+/+$ & $+/+$ & $+/+$ & $0 / 0$ & $0 / 0$ & $0 / 0$ & $0 / 0$ & $+/ 0$ \\
\hline 9 & Giardia & $+/+$ & $+/+$ & $+/+$ & $+/ 0$ & $0 / 0$ & $0 / 0$ & $0 / 0$ & $0 / 0$ \\
\hline 12 & Giardia & $+/+$ & $+/ 0$ & $+/ 0$ & $0 / 0$ & $0 / 0$ & $0 / 0$ & $0 / 0$ & $0 / 0$ \\
\hline 15 & Crypto & $0 / 0$ & $0 / 0$ & $0 / 0$ & $0 / 0$ & $+/+$ & $0 / 0$ & $+/+$ & $+/+$ \\
\hline 18 & Crypto & $0 / 0$ & $0 / 0$ & $0 / 0$ & $0 / 0$ & $+/+$ & $+/+$ & $+/ 0$ & $+/+$ \\
\hline 23 & Crypto & $0 / 0$ & $0 / 0$ & $0 / 0$ & $0 / 0$ & $0 / 0$ & $0 / 0$ & $0 / 0$ & $0 / 0$ \\
\hline 24 & Crypto & $0 / 0$ & $0 / 0$ & $0 / 0$ & $0 / 0$ & $+/+$ & $+/+$ & $0 / 0$ & $+/+$ \\
\hline 32 & undet & $+/+$ & $0 / 0$ & $0 / 0$ & $0 / 0$ & $0 / 0$ & $0 / 0$ & $0 / 0$ & $0 / 0$ \\
\hline 33 & undet & $+/ 0$ & $0 / 0$ & $0 / 0$ & $0 / 0$ & $0 / 0$ & $0 / 0$ & $0 / 0$ & $0 / 0$ \\
\hline 34 & undet & $+/+$ & $+/+$ & $+/+$ & $+/+$ & $0 / 0$ & $0 / 0$ & $0 / 0$ & $0 / 0$ \\
\hline 35 & undet & $+/+$ & $+/+$ & $+/+$ & $+/+$ & $0 / 0$ & $0 / 0$ & $0 / 0$ & $0 / 0$ \\
\hline 42 & undet & $0 / 0$ & $0 / 0$ & $0 / 0$ & $0 / 0$ & $+/+$ & $+/+$ & $+/+$ & $+/+$ \\
\hline 49 & undet & $+/+$ & $+/+$ & $+/+$ & $+/ 0$ & $0 / 0$ & $0 / 0$ & $0 / 0$ & $0 / 0$ \\
\hline Total positive & & 9 & 6 & 7 & 5 & 4 & 3 & 3 & 5 \\
\hline
\end{tabular}

Mic $=$ microscopy; undet $=$ undetected $+=$ positive; $0=$ negative. Results from duplicate tests are shown as $+/+,+/ \mathbf{0}$, and $0 / 0$. Discordant results are in bold. Kit A = in-house RT-PCR assays, kit B = RIDA GENE Parasitic Stool Panel (PG1705), kit C = LightMix Modular Gastroenteritis Assays, and kit D = BD MAX Enteric Parasite Panel.

study. Data were stored in an approved and secure portal belonging to Region of Southern Denmark.

\section{Results}

3.1. LIS Data. In the period of October 2005 to January 2015, 10593 samples from 4887 patients were examined for intestinal parasites. Based on microscopy the reported diarrhoeacausing parasites were G. lamblia (500 samples/237 patients), Cryptosporidium species (78 samples/41 patients), and E. histolytica or E. histolytica/dispar (159 samples/62 patients) and Cyclospora species (25 samples/12 patients). As previously described [10] the majority of parasites reported as E. histolytica after microscopy were most probably in fact $E$. dispar, which is considered nonpathogenic. On the basis of these data we decided in the study to test for $G$. lamblia and C. parvum/C. hominis because of the frequencies by which they cause disease. For Cryptosporidium sp. the severe illness it causes in immunocompromised patients and the importance to public health as an agent of food and water borne outbreaks also contributed to the decision. In addition a test for E. histolytica was included because amoebic dysentery and amoebic liver abscess are severe conditions requiring immediate and appropriate treatment. Thus only the rare cases of cyclosporiasis (approximately one per year in our diagnostic laboratory) would be missed because of the selection of targets.

3.2. Objective 1. The in-house RT-PCR assay for G. lamblia was positive in 13 of the 14 microscopy-positive samples and in 5 microscopy-negative samples. All three tested RTPCR assays for C. parvum/C. hominis were positive in ten of the eleven microscopy-positive samples as well as in one microscopy-negative sample. The selected species-specific inhouse RT-PCR assays detected the expected pathogen in all the microscopy-positive samples except for one sample (number 6, Table 2) which based on microscopy was reported with G. lamblia and one sample (number 23, Table 2) with Cryptosporidium spp. As none of the RT-PCR assays or MTPCR kits detected the expected parasites in these samples they may represent false positive microscopy reporting (Table 2). The Cryptosporidium assay 3 identified C. hominis in four and C. parvum in eight samples. The E. histolytica RTPCR assay was only positive in 1 of 8 microscopy-positive samples and none of the microscopy-negative samples. The seven microscopy-positive samples that were negative for $E$. histolytica by PCR were all positive when analysed for $E$. dispar by species-specific PCR.

There was no statistical difference in the number of positive samples when tested by microscopy and PCR for the three selected parasites $(p=0,22)$.

3.3. Objective 2. Kit A detected G. lamblia in three samples more than kit $\mathrm{B}$, two samples more than kit $\mathrm{C}$, and four samples more than kit D. For C. parvum/C. hominis, kit A detected one positive sample more than kit $B$ and one positive sample more than kit $\mathrm{C}$ but one less than kit D. Only kit D was positive for C. parvum/C. hominis in sample (number 8) in which the other kits detected G. lamblia (Table 2). All kits detected E. histolytica in the same sample. 
Of all samples tested, discordant results were obtained from duplicate determinations in one sample using in-house assays (kit A), two using kit B, two using kit $\mathrm{C}$, and three using kit D (Table 2).

None of the MT-PCR kits confirmed the presence of $G$. lamblia in sample numbers 32 and 33, which were positive in two out of two and one of two replicates, respectively, by the in-house RT-PCR. These two samples were from the same patient. A sample three days later was positive when tested at the National Reference Laboratory at Statens Serum Institut. Sample numbers 32 and 33 were therefore considered to be true positive but weak.

Sample number 86 (not shown in Table 2) was only tested in kits A, B, and D and therefore not included in the total number. In this sample, kit B was positive for both $G$. lamblia and E. histolytica, in one out of two duplicates. This was not confirmed by any of the other test kits.

Inhibition by faecal constituents was not a problem in this study, as it has been reported previously [17].

\section{Discussion}

In this study we have evaluated PCR assays for replacement of microscopy for routine detection of diarrhoea-causing parasites. In contrast to microscopy PCR only detects specific parasites. Careful selection of targets for the PCR assays is therefore mandatory. It is also important to be aware of which diarrhoea-causing parasites present in the population that are not targeted by the selected PCR assays and the number of patients affected by exclusion of assays for particular rare parasites $[18,19]$.

Based on previous frequencies of detection by microscopy and severity of disease we decided to establish PCR assays for G. lamblia, C. parvum/C. hominis, and E. histolytica. The only diarrhoea-causing parasite previously detected and not targeted by the PCR assays was Cyclospora spp. with a little more than one case on average each year.

The three different assays for C. parvum/C. hominis performed equally but assay 1 resulted in the lowest CT values and was used for objective 2. Assay 3 distinguished between C. hominis and C. parvum and was used for subsequent species identification in positive samples. Rapid species identification is valuable for epidemiological investigations.

The in-house RT-PCR assays detected G. lamblia and Cryptosporidium spp. in microscopy-negative samples from patients suspected of suffering from intestinal parasitosis and thus appeared more sensitive than microscopy. PCR has previously been reported to be more sensitive than microscopy for detection of specific parasites. In ten Hove's study in 2007, PCR showed 3.6\% better sensitivity than microscopy for Giardia in clinical stool samples [3], and, in Starks study in 2011, PCR had 2.9\% better sensitivity for Giardia and 2\% better sensitivity for Cryptosporidium than microscopy [5]. We found PCR detected 4.1\% more Giardia than microscopy but did not find any difference for Cryptosporidium in this study. A major advantage of PCR over microscopy is the specificity obtained from the discrimination between $E$. histolytica and E. dispar [7-10]. Seven of the eight samples originally reported with E. histolytica by microscopy were negative in the in-house RT-PCR and were subsequently identified as E. dispar.

The comparison of four test kits, including the in-house assay based kit $\mathrm{A}$, showed varying results from replicate tests. Testing in single determinations may lead to false results in a minority of cases. Future use of these assays may be improved by running tests in duplicate.

The limitation of this study was first of all the sample size, which does not allow statistical analysis of differences in performance of microscopy and RT-PCR in-house assays. Tendencies in favour of the in-house assays were seen when comparing variation of replicates and sensitivities to commercial test kits.

As indicated by the numbers of cases of intestinal parasitosis registered in our LIS over the years, collection of larger number of samples will take time. The detection of parasites in microscopy-negative samples suggests that replacement of microscopy with PCR will increase the positive rates and thereby shorten the time needed to establish large sample collections.

\section{Conclusion}

In our setting it is relevant to test for G. lamblia, C. parvum/C. hominis, and E. histolytica. We expect that replacement of microscopy with in-house RT-PCR assays for these parasites will result in higher positive rates for G. lamblia and C. parvum/C. hominis, while false positive results for $E$. histolytica will be avoided. Addition of a secondary test differentiating between C. parvum and C. hominis will be of value for early discovery of outbreaks.

All the commercial MT-PCR kits evaluated here tested for the relevant targets. However, some variation in performance was seen when using the kits. The choice of method for detection of intestinal protozoa may depend on the setting. Compared to PCR microscopy is less sensitive and less specific, more time consuming, and more dependent on individual skills. Use of commercial PCR kits may be attractive in laboratories handling moderate numbers of samples, while in-house PCR assays can be established and maintained for large-scale throughput analyses, mainly due to lower costs.

\section{Disclosure}

The sponsors did not have any role in the study design, collection, analysis, and interpretation of data.

\section{Conflicts of Interest}

The authors declare no conflicts of interest.

\section{Acknowledgments}

The study is a part of a Ph.D. project and supported by grant from following Danish organizations: A.P. Møller Foundation for the Advancement of Medical Science, "Fonden for Læge Else Poulsens Mindelegat," Beckett-Fonden, Region Syddanmarks and Region Sjællands Fælles Forskningspulje, University of Southern Denmark, and the Department for 
Clinical Microbiology at Odense University Hospital. The authors thank the laboratory staff of the Sections of Parasitology in the Department for Clinical Microbiology at Odense University Hospital, Odense, Denmark, for their help in collecting the stool samples and the Department for Clinical Microbiology at Slagelse Hospital, Slagelse, Denmark, for use of their BD MAX system, specially Tina Vasehus Madsen, Ph.D., for assisting with the testing. They also thank Dr. Ming Chen in the Department for Clinical Microbiology, Hospital of Southern Jutland, Sønderborg, Denmark, for critically revising the paper.

\section{References}

[1] J. J. Verweij, R. A. Blangé, K. Templeton et al., "Simultaneous detection of Entamoeba histolytica, Giardia lamblia, and Cryptosporidium parvum in fecal samples by using multiplex realtime PCR," Journal of Clinical Microbiology, vol. 42, no. 3, pp. 1220-1223, 2004.

[2] T. Schuurman, P. Lankamp, A. van Belkum, M. Kooistra-Smid, and A. van Zwet, "Comparison of microscopy, real-time PCR and a rapid immunoassay for the detection of Giardia lamblia in human stool specimens," Clinical Microbiology and Infection, vol. 13, no. 12, pp. 1187-1191, 2007.

[3] R. ten Hove, T. Schuurman, M. Kooistra, L. Möller, L. Van Lieshout, and J. J. Verweij, "Detection of diarrhoea-causing protozoa in general practice patients in The Netherlands by multiplex real-time PCR," Clinical Microbiology and Infection, vol. 13, no. 10, pp. 1001-1007, 2007.

[4] L. E. S. Bruijnesteijn van Coppenraet, J. A. Wallinga, G. J. H. M. Ruijs, M. J. Bruins, and J. J. Verweij, "Parasitological diagnosis combining an internally controlled real-time PCR assay for the detection of four protozoa in stool samples with a testing algorithm for microscopy," Clinical Microbiology and Infection, vol. 15, no. 9, pp. 869-874, 2009.

[5] D. Stark, S. E. Al-Qassab, J. L. N. Barratt et al., "Evaluation of multiplex tandem real-time PCR for detection of cryptosporidium spp., Dientamoeba fragilis, Entamoeba histolytica, and Giardia intestinalis in clinical stool samples," Journal of Clinical Microbiology, vol. 49, no. 1, pp. 257-262, 2011.

[6] A. Kebede, J. J. Verweij, B. Petros, and A. M. Polderman, "Short communication: misleading microscopy in amoebiasis," Tropical Medicine and International Health, vol. 9, no. 5, pp. 651652, 2004.

[7] B. S. Ayed, B. R. Abdallah, M. Mousli, K. Aolin, M. Thellier, and A. Bouratbine, "Molecular differentiation of entamoeba histolytica and entamoeba dispar from Tunisian food handlers with amoeba infection initially diagnosed by microscopy," Parasite, vol. 15, no. 1, pp. 65-68, 2008.

[8] K. Khairnar, S. C. Parija, and R. Palaniappan, "Diagnosis of intestinal amoebiasis by using nested polymerase chain reaction-restriction fragment length polymorphism assay," Journal of Gastroenterology, vol. 42, no. 8, pp. 631-640, 2007.

[9] J. J. Verweij, F. Oostvogel, E. A. T. Brienen, A. Nang-Beifubah, J. Ziem, and A. M. Polderman, "Short communication: prevalence of entamoeba histolytica and entamoeba dispar in northern Ghana," Tropical Medicine and International Health, vol. 8, no. 12, pp. 1153-1156, 2003.

[10] G. N. Hartmeyer, S. V. Høgh, M. Chen, H. Holt, M. N. Skov, and M. Kemp, "Need for species-specific detection for the diagnosis of amoebiasis in a non-endemic setting," Scandinavian Journal of Infectious Diseases, vol. 45, no. 11, pp. 868-871, 2013.
[11] A. V. Allen and D. S. Ridley, "Further observations on the formol-ether concentration technique for faecal parasites.", Journal of Clinical Pathology, vol. 23, no. 6, pp. 545-546, 1970.

[12] S. A. Henriksen and J. F. Pohlenz, "Staining of cryptosporidia by a modified Ziehl-Neelsen technique," Acta veterinaria Scandinavica, vol. 22, no. 3-4, pp. 594-596, 1981.

[13] H. G. M. Niesters, "Quantitation of viral load using real-time amplification techniques," Methods, vol. 25, no. 4, pp. 419-429, 2001.

[14] M. Fontaine and E. Guillot, "Development of a TaqMan quantitative PCR assay specific for Cryptosporidium parvum," FEMS Microbiology Letters, vol. 214, no. 1, pp. 13-17, 2002.

[15] R. Yang, C. Murphy, Y. Song et al., "Specific and quantitative detection and identification of Cryptosporidium hominis and C. parvum in clinical and environmental samples," Experimental Parasitology, vol. 135, no. 1, pp. 142-147, 2013.

[16] C. R. Stensvold, M. Lebbad, J. J. Verweij et al., "Identification and delineation of members of the entamoeba complex by pyrosequencing," Molecular and Cellular Probes, vol. 24, no. 6, pp. 403-406, 2010.

[17] L. Monteiro, D. Bonnemaison, A. Vekris et al., "Complex polysaccharides as PCR inhibitors in feces: helicobacter pylori model," Journal of Clinical Microbiology, vol. 35, no. 4, pp. 995998, 1997.

[18] J. J. Verweij, "Application of PCR-based methods for diagnosis of intestinal parasitic infections in the clinical laboratory," Parasitology, vol. 141, no. 14, pp. 1863-1872, 2014.

[19] L. van Lieshout and J. J. Verweij, "Newer diagnostic approaches to intestinal protozoa," Current Opinion in Infectious Diseases, vol. 23, no. 5, pp. 488-493, 2010. 

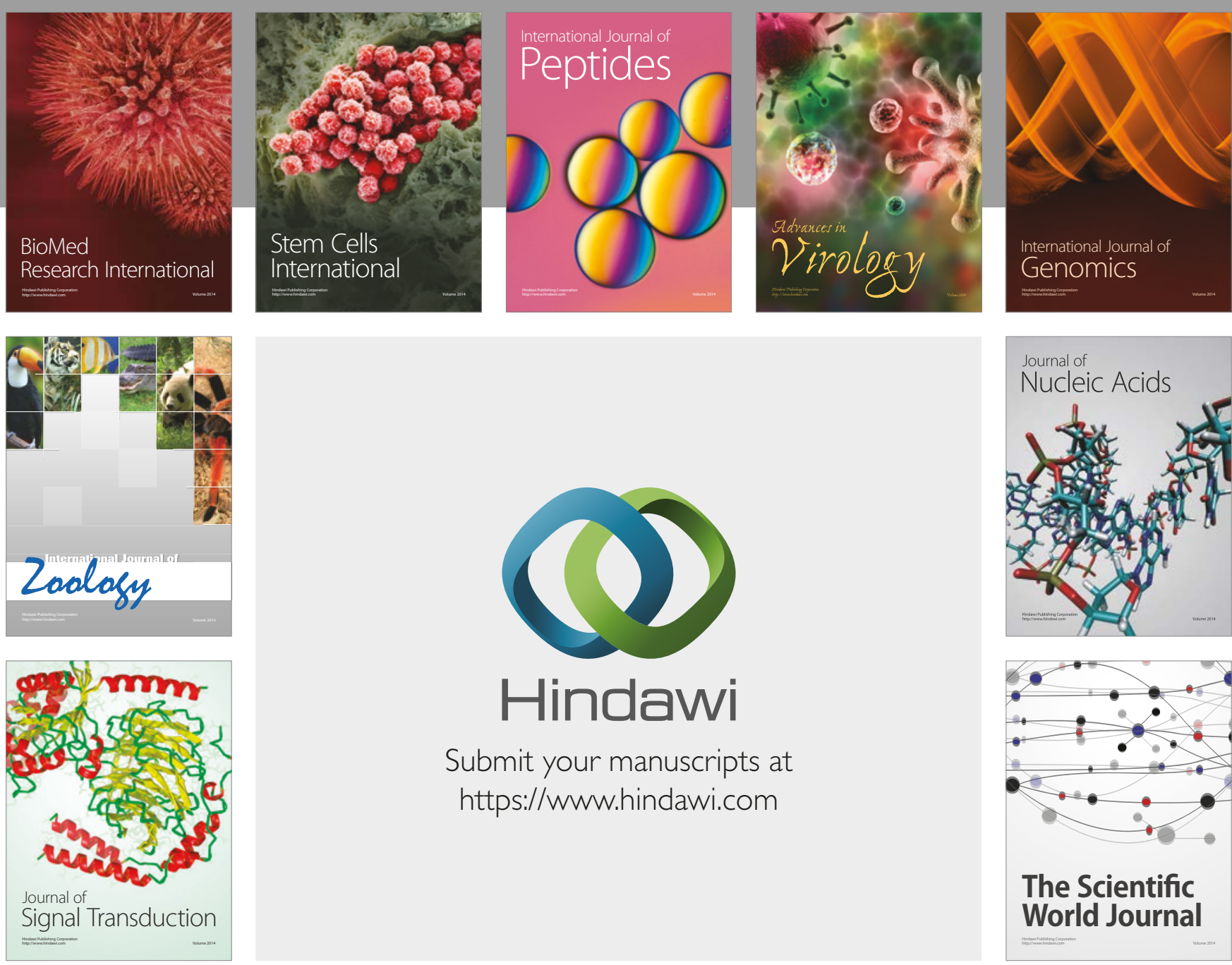

Submit your manuscripts at

https://www.hindawi.com
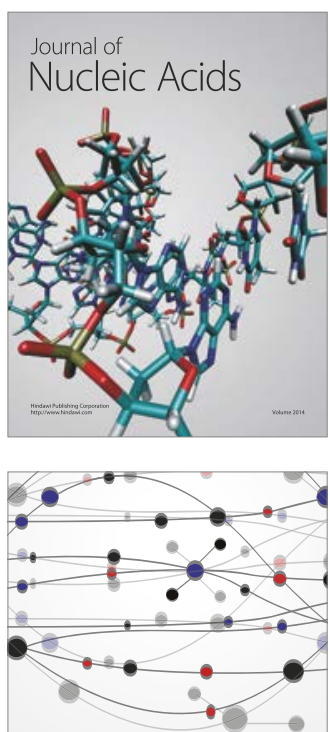

The Scientific World Journal

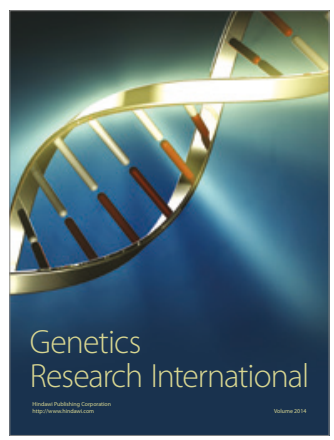

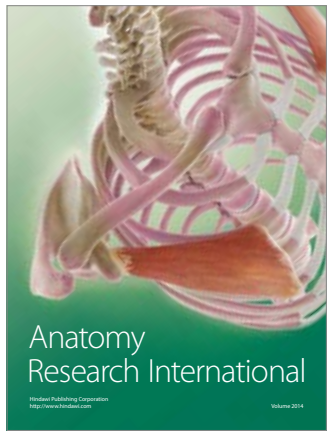

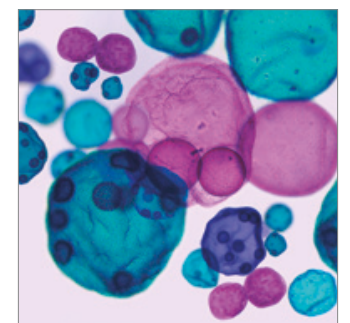

International Journal of Microbiology
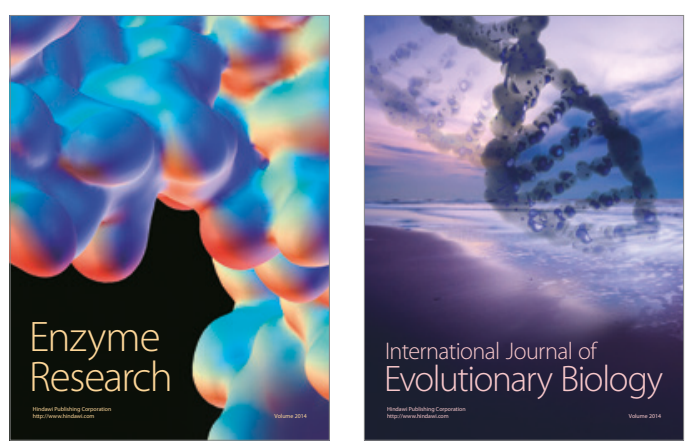
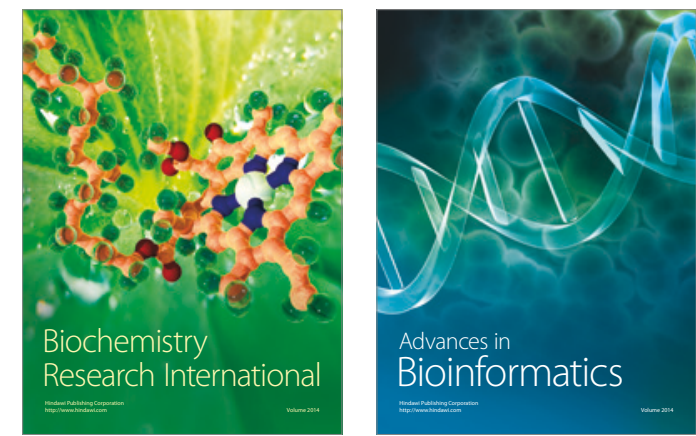

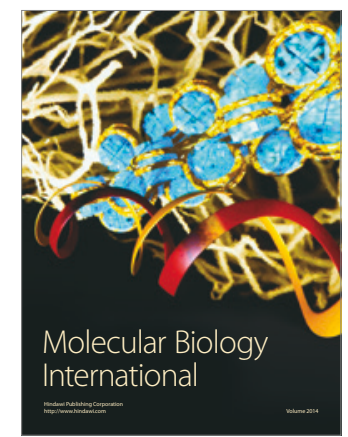

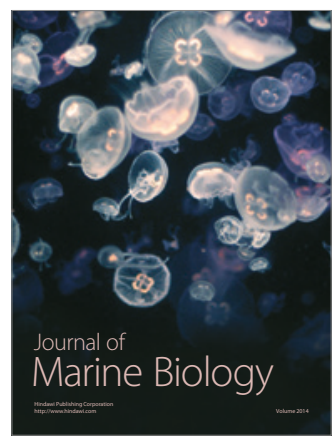

